\title{
AUTOMATIC EXTRACTION OF TIDE-COORDINATED SHORELINE USING OPEN SOURCE SOFTWARE AND LANDSAT IMAGERY
}

\author{
G. Gonçalves ${ }^{\mathrm{a}, \mathrm{b}, *}$, N. Duro ${ }^{\mathrm{c}}$, E. Sousa ${ }^{\mathrm{b}, \mathrm{d}}$, I. Figueiredo $^{\mathrm{b}, \mathrm{d}}$ \\ ${ }^{a}$ INESC-Coimbra, Rua Antero de Quental 199, 3000-033 Coimbra, Portugal \\ ${ }^{\mathrm{b}}$ Dept. of Mathematics, University of Coimbra, Portugal - gil@mat.uc.pt \\ ${ }^{\mathrm{c}}$ www.bluecover.pt, Portugal \\ ${ }^{\mathrm{d}}$ CMUC, Apartado 3008, EC Santa Cruz, 3001 - 50, Portugal
}

Commission VI, WG VI/4

KEY WORDS: Landsat, Open source software, instantaneous shoreline, tide-coordinate shoreline, Constrained Delaunay Triangulation

\begin{abstract}
:
Due to both natural and anthropogenic causes, the coastal lines keeps changing dynamically and continuously their shape, position and extend over time. In this paper we propose an approach to derive a tide-coordinate shoreline from two extracted instantaneous shorelines corresponding to a nearly low tide and high tide events. First, all the multispectral images are panshaperned to meet the 15 meters spatial resolution of the panchromatic images. Second, by using the Modification of Normalized Difference Water Index (MNDWI) and the kmeans clustering method we extract the raster shoreline for each image acquisition time. Third, each raster shoreline is smoothed and vectorized using a penalized least square method. Fourth, a 2D constrained Delaunay triangulation is built from the two extracted instantaneous shorelines with their respective heights interpolated from a Tidal gauche station. Finally, the desired tide-coordinate shoreline is interpolated from the previous triangular intertidal surface. The results show that an automatic tide-coordinated extraction method can be efficiently implemented using free available remote sensing imagery data (Landsat 8) and open source software (QGIS and Orfeo toolbox) and python scripting for task automation and software integration.
\end{abstract}

\section{INTRODUCTION}

Coastal zones are one of the most dynamic environments on Earth's surface. They are defined by International Geosphere Biosphere Programme (IGBP) as the zones delimited inferiorly by the $200 \mathrm{~m}$ bathymetric contour and superiorly by $200 \mathrm{~m}$ topographic contour. The shoreline (also known as coastline in the Remote Sensing community) is ideally defined as the physical interface between land and water and is also the most dynamic part of the coastal zone. Shorelines can also be considered one of the most important Earth's terrain features, as $84 \%$ of the countries in the world have shorelines adjacent to open oceans, inland seas or both (Martnez et al., 2007). Moreover, due to both natural and anthropogenic causes, the shoreline keeps changing dynamically and continuously their shape, position and extend over time (Boak and Turner, 2005).

Detection, extraction and monitoring the shoreline are regarded as important tasks in safe navigation, coastal zone management and environmental protection, sustainable coastal development and planning (Gens, 2010). Because of the dynamic nature of the ocean waters and of the near coastal lands we need to introduce the definiton of instantaneous shoreline to point out that line position is relative to a given instant of time (Li et al., 2002). Thus, the shoreline needs to be defined in a stable vertical datum in order to be used as a reference shoreline. If this vertical datum is defined as the linear intersection between the coastal surface and a desired water tidal level, the shoreline is called tide-coordinated shoreline (Li et al., 2002).

To date a variety of data sources have been used to map the position of the shoreline. As examples of these data sources we can find historical terrestrial images, coastal maps and charts, aerial

${ }^{*}$ Corresponding author images, beach surveys, differential GNSS surveys and Remote Sensing techniques, such as, Multispectral/Hyperspectral imaging, airborne LiDAR (Light Detection and Ranging) data microwave sensors and video imaging (Boak and Turner, 2005). Multispectral satellite imagery offers the advantage of having numerous data records, the availability of repeated images for a single place at different times and the near global coverage of the entire Earth's surface. Moreover, since 2008 the United States Geological survey (USGS) has freely provided access to all archived images (Pardo-Pascual et al., 2012). In this paper we use Landsat8 images as the main data source for extracting the tide-coordinated shoreline.

Although much of the published literature have studied the problem of shoreline position from multispectral images, only a few papers have addressed correctly the problem of mapping the tidecoordinated shoreline. In this paper we propose a novel approach to derive a tide-coordinate shoreline from two extracted instantaneous shorelines correspondent to a nearly low tide and high tide events. First all the multispectral Landsat- 8 images are panshaperned to meet the 15 meters spatial resolution of the panchromatic images. Second, using the Modification of Normalized Difference Water Index (MNDWI) and the kmeans clustering method we extract the raster shoreline for each image acquisition time. Third, each raster shoreline is smoothed and vectorized using a Douglas-Peucker generalization method followed by a penalized least-square method. Fourth, a 2D constrained Delaunay triangulation is built from the two extracted instantaneous shorelines with their respective heights interpolated from a Tidal gauche station. Finally, the desired tide-coordinate shoreline is interpolated from the previous triangular intertidal surface and compared to the extracted shoreline for the given tidal height. 


\section{STUDY AREA AND IMAGE DATA}

The study area is a sandy beach stretch of $75 \mathrm{~km}$ located in the Portuguese north-west coast and is one of the most dynamic areas of the Portuguese west littoral (Baptista et al., 2011). This coastline stretch is characterised morphologically by a sandy shore, exposed directly to highly energetic waves, and by primary sand dunes (frontal dunes) with its baseline forming a relatively straight alignment. For the last years this stretch has been subjected to critical erosion and some of the primary sand dunes suffered an erosion rate of 10m/y (Baptista et al., 2011).

The Landsat imagery was downloaded from the US Geological Survey web site (http://glovis.usgs.gov/). For downloading some important criteria have been defined for image selection: i) if possible all the images have been acquired more or less at the same time of the year; ii) only the images with the best radiometric and atmospheric (free coastline cloud cover) have been selected. Table 1 shows the specifications of satellite data used in this study. The estimated tidal height is interpolated using the equations given in section 3.4. Figure 1 shows the three Landsat-

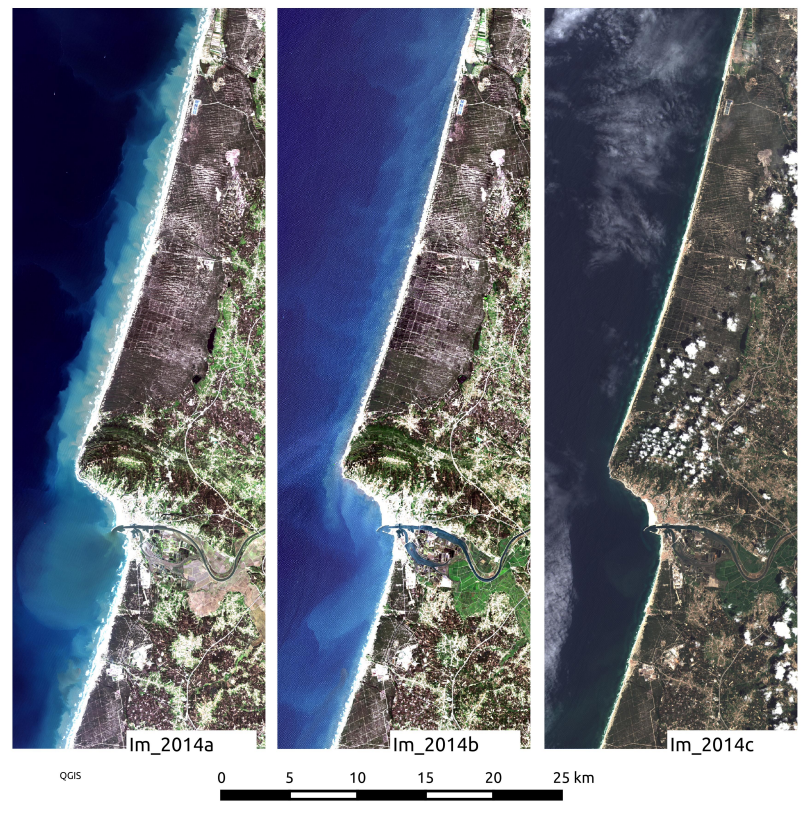

Figure 1: Landsat-8 images used in this study

8 images used in this study to extract the instantaneous shoreline. The first two images (2014a and 2014b) are used for interpolating the tide-coordinated shoreline and the last image (2014c) it is used with the purpose of checking.

\section{METHODOLOGY}

The overall methodology is shown in figure 2. It is mainly composed by two separate stages. In the first stage we extract two shorelines corresponding to one high and one low tide, using the MNDWI index and the k-means clustering technique. In the second stage we use these two extracted shorelines to interpolate the tide-coordinated shoreline for the desired water level.

\subsection{Pan-sharpening}

Pan-shapening is used for merging the high spatial resolution $(15 \mathrm{~m})$ panchromatic Landsat- 8 band with the medium spatial resolution $(30 \mathrm{~m})$ multispectral bands to create a multispectral image containing the higher resolution spatial features such as the

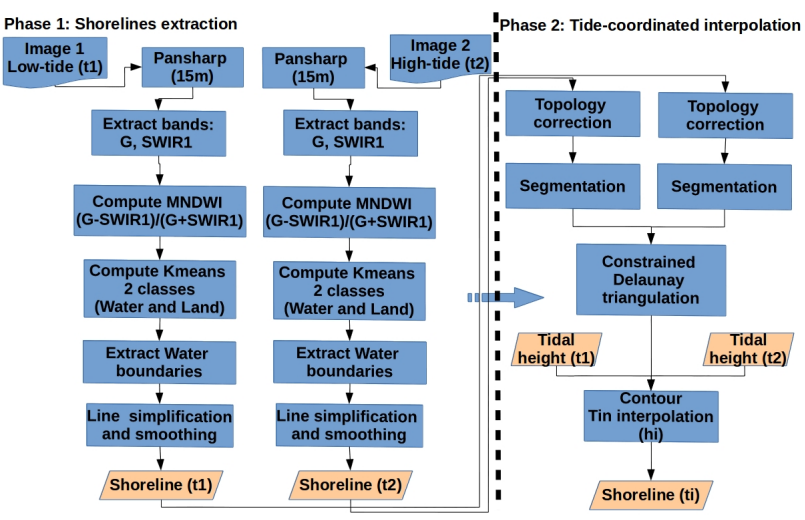

Figure 2: Methodology flowchart

shoreline undulations. This pan-sharpened image will support the shoreline extraction process with a spatial resolution compatible with the detail of $15 \mathrm{~m}$ spatial features. In this paper we use the Bayesian data Fusion method (Fasbender et al., 2008) for the pansharpening process and a bicubic interpolation for resample the multispectral bands to the resolution of the panchromatic band.

\subsection{Instantaneous shoreline detection and extraction}

The extraction of water information from multispectral satellite images can be done by analysing the signatures of each ground target among the different spectral bands and using these signatures as input for a specific classification method. Another way is using a band ratio approach of two spectral bands. Ratio images are calculated by dividing for each pixel the DN values in one spectral band by the corresponding pixel value in another band. The advantages of using the band ratio approaches compared to the other approaches is that the environmental induced variations in the DN values of a single spectral band are reduced by considering the ratio between two bands ((Song et al., 2001), (Tran and Trinh, 2009)). In this paper we use the Modified Normalized Difference Water Index (MNDWI) as it can efficiently suppress from the water information the noise coming from built-up land, vegetation and soil (Xu, 2006)

$$
M N D W I=\frac{\text { Green }- \text { Swir } 1}{\text { Green }+ \text { Swir } 1}
$$

After calculating the MNDWI for each image, the kmeans clustering method is used to separate the water from land, using the fact that the centre values of the water cluster are always greater than zero.

\subsection{Smoothing shorelines}

To smooth the extracted raster shoreline we use the robust and fully automated smoothing procedure proposed by (Garcia, 2010). This procedure involves the use of a discrete cosine transform to solve the following linear system that allows the determination of the smoothed data $(\hat{y})$ :

$$
\left(I_{n}+s D^{\top} D\right) \hat{y}=y
$$

where $y$ is the the raster shoreline (vectorial line defined by the centres of the n extracted shoreline pixels), $s$ is the smoothing parameter, $D$ is a triagonal square matrix expressing the 2 nd order divided differences, and $I_{n}$ is the $n \times n$ identity matrix. Since 


\begin{tabular}{cccccccc}
\hline \multicolumn{2}{c}{ Images } & & & \multicolumn{3}{c}{ Tide } \\
\hline \multirow{2}{*}{ Row-Path } & Date & Sensor & $\begin{array}{c}\text { Image } \\
\text { name }\end{array}$ & $\begin{array}{c}\text { Acq. } \\
\text { GMT }\end{array}$ & $\begin{array}{c}\text { Max } \\
\text { GMT - h }(\mathrm{m})\end{array}$ & $\begin{array}{c}\text { Min } \\
\text { GMT - h (m) }\end{array}$ & $\begin{array}{c}\text { Estim. } \\
\mathrm{h}(\mathrm{m})\end{array}$ \\
\hline \multirow{3}{*}{$204-032$} & $2014-03-19$ & & $2014 \mathrm{a}$ & $11: 14$ & $16: 43-3.38$ & $10: 16-0.60$ & 0.8 \\
& $2014-07-09$ & \multirow{2}{*}{ OLI } & $2014 \mathrm{~b}$ & $11: 14$ & $12: 10-3.05$ & $05: 50-1.04$ & 2.9 \\
& $2014-08-10$ & & $2014 \mathrm{c}$ & $11: 14$ & $14: 25-3.75$ & $08: 05-0.47$ & 2.1 \\
\hline
\end{tabular}

Table 1: Image date and tidal conditions during image acquisition.

the data are equally spaced (note that we are dealing with a raster line) the equation 2 can be rewritten as (Garcia, 2010):

$$
\hat{y}=\operatorname{ICDT}(\Gamma \cdot \operatorname{CDT}(y))
$$

where $\Gamma$ is a diagonal matrix whose elements are given by $\Gamma_{i, i}=$ $\left[1+s(2-2 \cos ((i-1) \pi / n))^{2}\right]^{-1}$, CDT and ICDT are the discrete cosine transform and the inverse discrete cosine transform, respectively. The smoothing parameter $s$ can either be automatically estimated by the method of generalized cross-validation (GCV) or be manually set to a fixed value (see figure 3 ). In this paper the smoothing parameter has been set automatically by GCV.

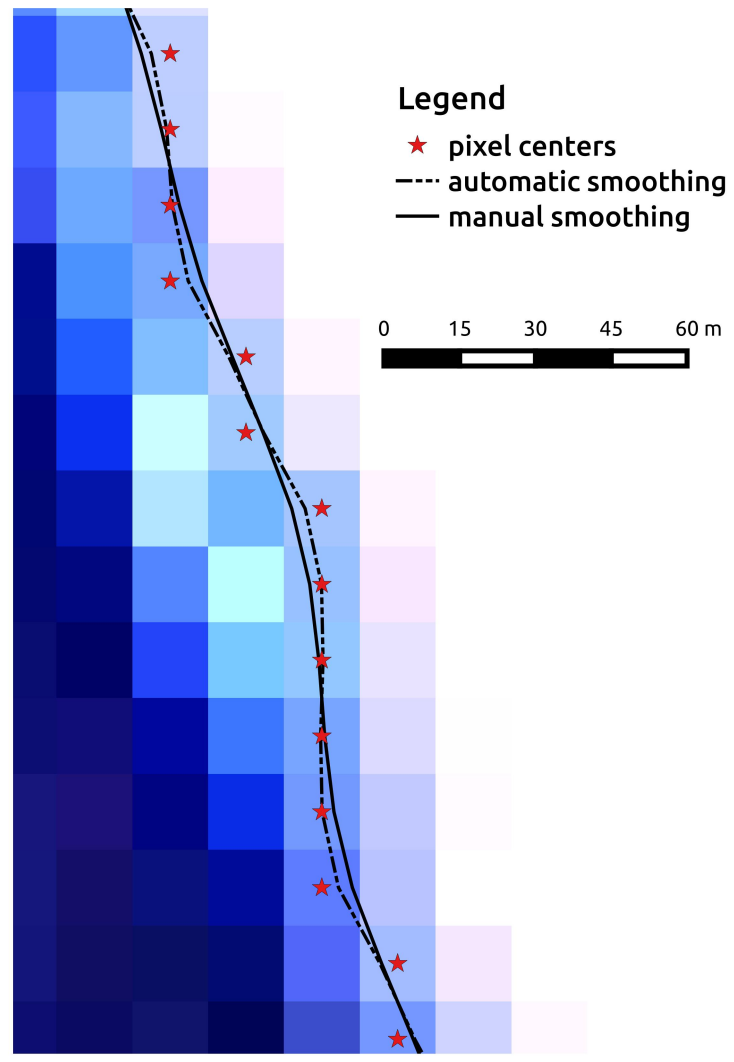

Figure 3: Shoreline smoothing using CDT

\subsection{Tide-coordinated shoreline interpolation}

As the accuracy of the shoreline position extracted from satellite images depends on the range of tidal height at the satellite overpass time (Yu et al., 2011), it is important to estimate the tidal height $(y)$ at the time of image acquisition $(t)$. Denoting by $h_{\max }$ the height of the high tide, $h_{\min }$ the height of low tide, $\Delta T$ the time interval between the low and the high tide, and $\Delta t$ the time interval between the preceding event (high or low tide) and the time of image acquisition the tidal height can be estimated using the following equation:

$$
y=\frac{h_{\max }+h_{\min }}{2} \pm \frac{h_{\max }-h_{\min }}{2} \cos \frac{\pi \Delta t}{\Delta T}
$$

where the minus symbol should be used in case the preceding event is a low tide. For each image we use equation 4 to interpolate the tidal height at the satellite overpass (see Table 1). These tidal heights are necessary for interpolating, from the extracted shorelines, the tide-coordinate shoreline at the desired tidal height.

Because we use a constrained Delaunay triangulation (Shewchuk, 1996) for linear interpolation between the two shorelines, the shorelines have to be first corrected topologically and then segmented (i.e splitted) at the intersection points. The topological line correction will delete the most common line errors such as self-intersection arcs (weird polygons) and zero-length arcs. The segmentation of each line at the intersection points will create line segments with a correct topology suitable for subsquente 2D constrained triangulation.

\section{RESULTS}

\subsection{Phase 1: Instantaneous shoreline extraction}

In figure 4 we display the results of the instantaneous shoreline extraction for the case of the three images that are given in table 1. Three small areas are shown in detail in figures 4 .a, 4-b and 4-c. We observe that the extraction process based on the MNDWI index is insensitive to the foam of the ocean waves.

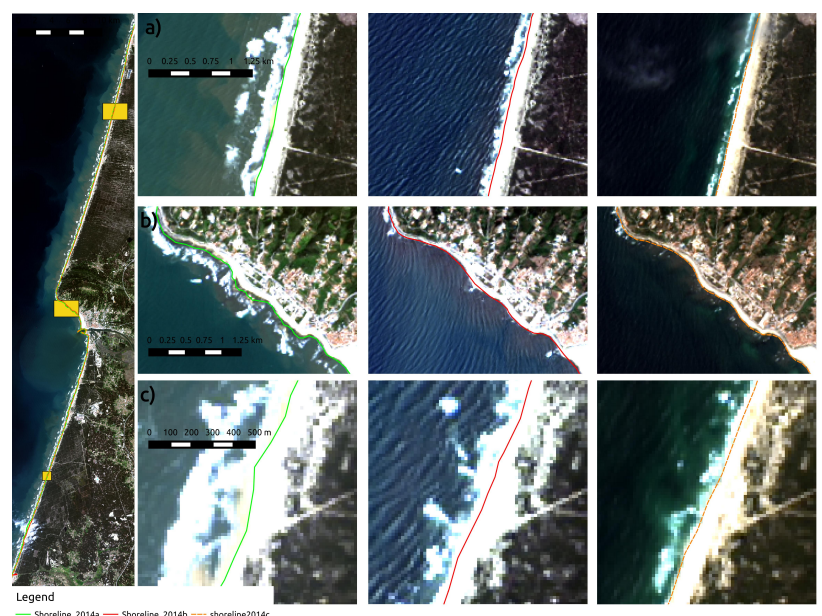

Figure 4: Extracted instantaneous shorelines

\subsection{Phase 2: Tide-coordinated shoreline interpolation}

The estimated tidal heights for the three Landsat- 8 images are shown in table 1 at the time of image acquisition. For the $3 \mathrm{im}$ ages used in this study the tidal height varies between $0.8 \mathrm{~m}$ to $2.9 \mathrm{~m}$. In order to interpolate the tide-coordinated shoreline we 
use the images 2014a and 2014b for delineating the area between the low and the high tide (Murray et al., 2012).

Figure 5 shows the results of the tide-coordinated shoreline interpolation. In figures 5-a) and 5-b) we can see in detail the results of the constrained interpolation for two small areas. In case a), as expected, we have a high tide shoreline closer to land line than the low tide. However, in case b) we have a mixed situation: the high tide shoreline changes from the line closer to land to the farthest line. In fact, as this is an area with high dynamics, the beach slope can change quickly causing a change in the shoreline position.

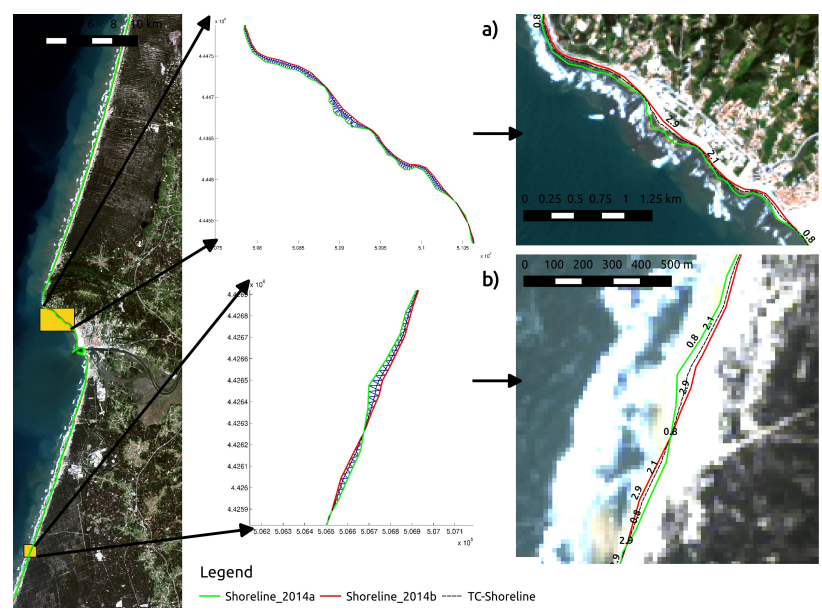

Figure 5: Interpolation of the tide-coordinated shoreline for two areas a) and b) with Im_2014a in background.

Finally, figure 6 shows the comparison between the horizontal position of the tide-coordinated shoreline interpolated for the tidal height of the acquisition time of the image $2014 \mathrm{c}$ (i.e $2.1 \mathrm{~m}$ ) and the instantaneous shoreline extracted from this image (i.e shoreline2014c). In general, a good agreement has been reached between these two shorelines, which proves the effectiveness of the proposed methodology.

\section{CONCLUSIONS}

In this paper we have proposed a methodology for extracting a tide-coordinated shoreline from two Landsat- 8 images corresponding to a low and high tidal conditions. Assuming that the beach slope remains constant between a given time period for which we have two images corresponding to a low tide and a high tide we have proposed a methodology to interpolate a tidecoordinated shoreline for a given tidal height.

The results have shown that an automatic tide-coordinated extraction method can be efficiently implemented using free available remote sensing imagery data (Landsat 8 ) and open source software (QGIS and Orfeo toolbox) and python scripting for task automation and software integration.

Further developments will include: i) the implementation of an automated procedure for topological error detection and correction and ii) the use of a distance metric to evaluate numerically the interpolated tide-coordinated shoreline and the instantaneous shoreline.

\section{ACKNOWLEDGEMENTS}

This work was partially supported by the Foundation for Science and Technology (FCT) of Portugal in the framework of the

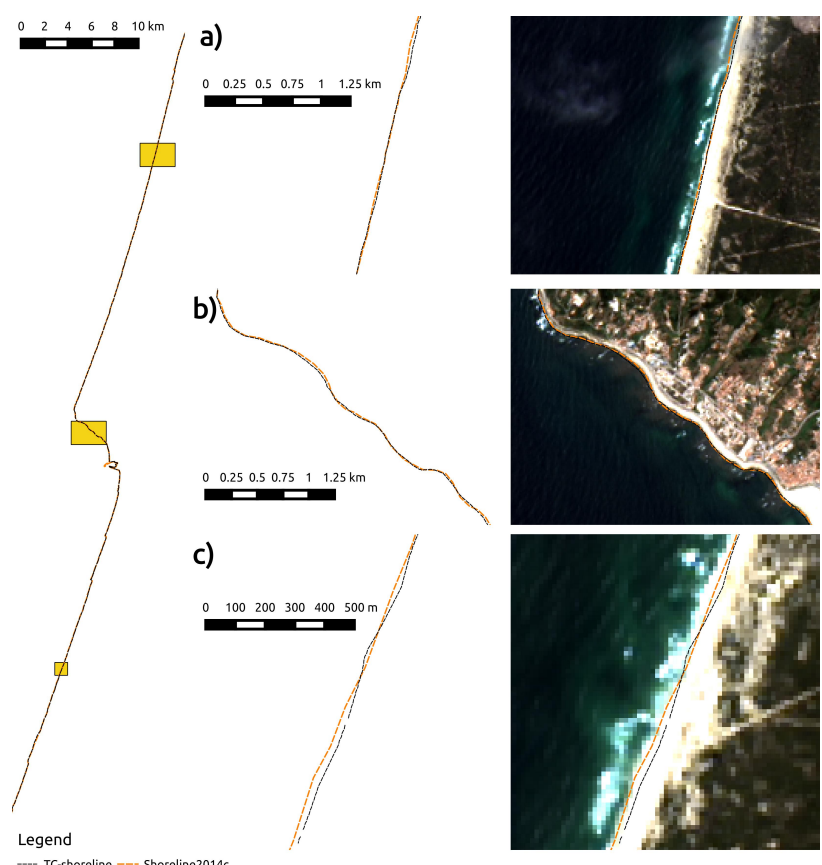

Figure 6: Comparison of the interpolated tide-coordinated shoreline with the instantaneous shoreline.

project PTDC/MAT-NAN/0593/2012 through European program COMPETE/FEDER and project PEst-OE/EEI/UI308/2014.

\section{REFERENCES}

Baptista, P., Cunha, T., Bernardes, C., Gama, C., Ferreira, O. and Dias, A., 2011. A precise and efficient methodology to analyse the shoreline displacement rate. Journal of Coastal Research 27(2), pp. 223-232.

Boak, E. H. and Turner, I. L., 2005. Shoreline definition and detection: A review. Journal of Coastal Research pp. 688-703.

Fasbender, D., Radoux, J. and Bogaert, P., 2008. Bayesian data fusion for adaptable image pansharpening. Geoscience and Remote Sensing, IEEE Transactions on 46(6), pp. 1847-1857.

Garcia, D., 2010. Robust smoothing of gridded data in one and higher dimensions with missing values. Computational Statistics \& Data Analysis 54(4), pp. 1167 - 1178.

Gens, R., 2010. Remote sensing of coastlines: detection, extraction and monitoring. International Journal of Remote Sensing 31(7), pp. 1819-1836.

Li, R., Ma, R. and Di, K., 2002. Digital tide-coordinated shoreline. Marine Geodesy 25(1-2), pp. 27-36.

Martnez, M., Intralawan, A., Vzquez, G., Prez-Maqueo, O., Sutton, P. and Landgrave, R., 2007. The coasts of our world: Ecological, economic and social importance. Ecological Economics 63(23), pp. 254 - 272. Ecological Economics of Coastal Disasters Coastal Disasters Special Section.

Murray, N. J., Phinn, S. R., Clemens, R. S., Roelfsema, C. M. and Fuller, R. A., 2012. Continental scale mapping of tidal flats across east asia using the landsat archive. Remote Sensing 4(11), pp. 3417-3426.

Pardo-Pascual, J. E., Almonacid-Caballer, J., Ruiz, L. A. and Palomar-Vázquez, J., 2012. Automatic extraction of shorelines from landsat TM and ETM+ multi-temporal images with subpixel precision. Remote Sensing of Environment 123, pp. 1-11. 
Shewchuk, J. R., 1996. Triangle: Engineering a 2D Quality Mesh Generator and Delaunay Triangulator. In: M. C. Lin and D. Manocha (eds), Applied Computational Geometry: Towards Geometric Engineering, Lecture Notes in Computer Science, Vol. 1148, Springer-Verlag, pp. 203-222. From the First ACM Workshop on Applied Computational Geometry.

Song, C., Woodcock, C. E., Seto, K. C., Lenney, M. P. and Macomber, S. A., 2001. Classification and change detection using landsat $\{\mathrm{TM}\}$ data: When and how to correct atmospheric effects? Remote Sensing of Environment 75(2), pp. 230 - 244.

Tran, T. V. and Trinh, T. B., 2009. Application of remote sensing for shoreline change detection in cuu long estuary. VNU Journal of Science, Earth Sciences 25(4), pp. 217-222.

Yu, K., Hu, C., Muller-Karger, F. E., Lu, D. and Soto, I., 2011. Shoreline changes in west-central florida between 1987 and 2008 from landsat observations. International Journal of Remote Sensing 32(23), pp. 8299-8313. 